Practical Measurements. By A. W. Siddons and A. Vassall. Cambridge, The University Press, 1910 . xiv $+60 \mathrm{pp}$.

THE definite purpose of this little note-book is to furnish for the boys at Harrow a series of elementary experiments in measuring and weighing, conforming with the recommendations embodied in the recent report on "The correlation of mathematical and science teaching" drawn up by a joint committee of the mathematics and science teachers of England.

On the mathematical side the experiments deal with the measurements, correct to three significant figures, and the necessary computations - of lengths, areas, and volumes - a practical checking up on the theorems of geometry.

The experiments emphasizing the side of physics deal with the weighing of liquids and solids and the determination of their specific gravities. Experiments with the hydrometer, barometer, pendulum, the U tube, and on Boyle's law are included. In the appendix experiments with the vernier, micrometer screw-gauge, and spherometer are added.

The methods used throughout the book are its strongest feature. Boys thoroughly grounded in the fundamental principles emphasized throughout will be able to do their future work with greater efficiency. Accuracy in estimating, measuring, computing, laying out to scale, and orderly arrangement are required. Concrete results, which should check up with theory, are required throughout. The practice of requiring such definite results, correct to a certain number of significant figures, is well worth while.

Ernest W. Ponzer.

Azimuth. By G. L. Hosmer. New York, John Wiley and Sons, $1909 . \mathrm{v}+73 \mathrm{pp}$.

IN ordinary engineering practice the determination of the azimuth of some line of a survey by astronomical means is not necessary; and in the cases where it is necessary, or at least advisable, the determination is likely to be a serious matter for many a practical surveyor-not because of any inherent difficulty in making or reducing the observations with all the accuracy that is needed in the field, but because the available methods are scattered in books which stay at home. Hence the utility of Hosmer's Azimuth, wherein are collected and explained with all simplicity various practicable field methods of fixing the true bearing of a line to minutes (or even to within 
a few seconds). In so short space may ample descriptive matter and illustrated examples be put that only about half the book, small as it is, is used for the purpose; the other half consists of the requisite astronomical, physical, and mathematical tables. The surveyor who is no astronomer need have no fear. The author requires of him no knowledge of theoretical or practical astronomy or of uranography-except that the totally ignorant might have difficulty in picking out Markab ( $\alpha$ Pegasi) from the chart on which there are two $\alpha$ 's in the great square of Pegasus.

E. B. Wilson.

\section{EISENHART'S DIFFERENTIAL GEOMETRY.}

IN reviewing Professor L. P. Eisenhart's book on Differential Geometry in the June number of the Bulletin, I criticized four equations which occur at the bottom of page 313 without noticing that the arc is supposed to be the parameter along the locus of the centers of the spheres, as is stated in the last paragraph of page 310 . The equations are correct as they stand with the exception of a plus sign between the parentheses in the third, which should be minus.

Professor Eisenhart has sent me the following list of errata, the publication of which may be of convenience to readers of the book:

P. 51, Ex. 24 is incorrect.

P. 87, omit the last line.

P. 117, to the expression for $\frac{d^{2} x}{d s^{2}}$ add $\frac{\partial x}{\partial u} \frac{d^{2} u}{d s^{2}}+\frac{\partial x}{\partial v} \frac{d^{2} v}{d s^{2}}$.

P. 123, last paragraph is incorrect. The position of the surface relative to the tangent plane depends upon the character of the terms of third and higher orders.

P. 179 , in (86) the signs + should be -, and in the next equation the signs - should be + .

P. 180 , line 27 , change $S$ to $S_{2}$.

P. 221, line 24, the upper limit of the second integral should be $u_{2}$ instead of $u$.

P. 241, in (52) change $y_{1}$ to $y_{0}^{\prime}$.

P. 259, line 3 , in place of "congruent" read "superposable by a translation." 